\section{Commentary: Is the need for permanent pacemaker after aortic valve replacement such a big deal?}

\author{
Sarah Yousef, MD, ${ }^{a}$ and Danny Chu, MD ${ }^{a, b}$
}

Sutureless and rapid deployment aortic valve replacement (SURD-AVR) has emerged over the past few decades, offering a middle ground between transcatheter AVR (TAVR) and conventional surgical AVR (SAVR). Through a standard surgical approach, these valves are implanted with only 3 guiding sutures, allowing for reduced crossclamp and cardiopulmonary bypass times, while also providing excellent hemodynamic parameters. ${ }^{1,2}$ The Intuity Elite Valve (IEV) (Edwards Lifesciences, Irvine, Calif) is a rapid deployment valve fixed in the subannular region. As such, the risk of conduction abnormalities potentially requiring permanent pacemaker (PPM) implantation is expected to be higher than with SAVR. Yet, some studies have found that risk of PPM is not significantly associated with type of valve prosthesis. Rather, preoperative conduction disturbances were found to be predictive of PPM need. SURDAVR was, however, associated with a greater incidence of new-onset left bundle branch block (LBBB) when compared with SAVR. ${ }^{3,4}$

Thuraisingam and Newcomb ${ }^{5}$ evaluate rhythm disturbances and conduction abnormalities following IEV implantation by comparing postoperative electrocardiographs (EKGs) to baseline. Only $60 \%$ of patients were in normal

\footnotetext{
From the ${ }^{\text {aDivision }}$ of Cardiac Surgery, Department of Cardiothoracic Surgery, University of Pittsburgh School of Medicine, Pittsburgh, Pa; and ${ }^{\mathrm{b}} \mathrm{Heart}$ and Vascular Institute, University of Pittsburgh Medical Center, Pittsburgh, $\mathrm{Pa}$

Disclosures: Dr Chu is an international proctor/consultant for the Japanese Organization for Medical Device Development Inc, a member of The Osler Institute faculty, and a journal editor for Wolters Kluwer Health. Dr Yousef reported no conflicts of interest.

The Journal policy requires editors and reviewers to disclose conflicts of interest and to decline handling or reviewing manuscripts for which they may have a conflict of interest. The editors and reviewers of this article have no conflicts of interest.

Received for publication Oct 8, 2021; revisions received Oct 8, 2021; accepted for publication Oct 21, 2021; available ahead of print Oct 26, 2021.

Address for reprints: Danny Chu, MD, Division of Cardiac Surgery, Department of Cardiothoracic Surgery, University of Pittsburgh School of Medicine, 200 Lothrop St, Suite C-700, Pittsburgh, PA 15213 (E-mail: chud@upmc.edu).

JTCVS Techniques 2021;10:229-30

2666-2507

Copyright (c) 2021 The Author(s). Published by Elsevier Inc. on behalf of The American Association for Thoracic Surgery. This is an open access article under the CC BY-NC-ND license (http://creativecommons.org/licenses/by-nc-nd/4.0/).

https://doi.org/10.1016/j.xjtc.2021.10.045
}

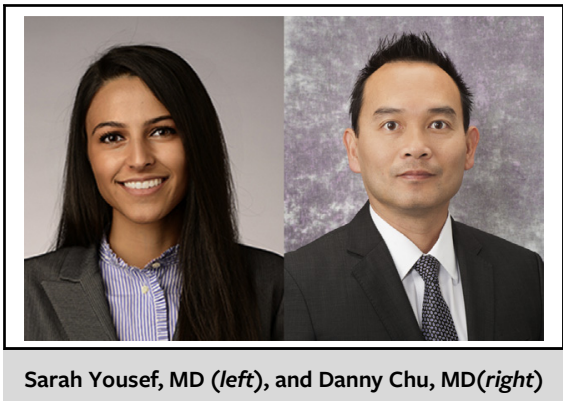

CENTRAL MESSAGE

Permanent pacemaker implanta-

tion after aortic valve replace-

ment is associated with

significant morbidity. Chronicity

of rhythm disturbances and

optimal timing of pacemaker

insertion remain unclear.

sinus rhythm without conduction abnormalities preoperatively. Roughly $18 \%$ of patients had developed new LBBB at postoperative day 5 , with only $4 \%$ persisting at week 6 . Widened QRS complex at postoperative day 5 was found to be associated with PPM need. Of the 97 patients, 14 $(14.4 \%)$ required a permanent pacemaker, but none were in a paced rhythm at 6 weeks. Only half of the patients requiring PPM had an isolated rapid-deployment AVR (RDAVR), whereas the other half had concomitant procedures.

The topic of this study is highly relevant because interest in pacemaker dependency has resurfaced with the rise of TAVR and SURD-AVR. The need for postoperative PPM is significant because of the associated risks of device malfunction, infection, tricuspid regurgitation, heart failure, and thrombotic events. ${ }^{6}$ Furthermore, the current evidence shows an apparent increase in mortality among TAVR patients who develop a new-onset LBBB and require PPM implantation postoperatively. ${ }^{7}$ The authors review the relevant literature, describe their methods of IEV implantation, and offer an explanation for the rate of conduction abnormalities seen after RDAVR. Their findings raise pertinent questions regarding the transient versus persistent nature of conduction abnormalities after RDAVR, as well as the optimal timing of PPM implantation. However, long-term follow-up data are needed to answer these questions and are unfortunately lacking in this study. 
In fact, follow-up only consisted of spot EKGs at 2 isolated time points, limiting insight on emergence and persistence of rhythm disturbances following SURDAVR. The study is also limited by its retrospective single-center, single-surgeon design and small sample size. Larger studies with longer follow-up and more frequent evaluation of rhythm over time are warranted. Such studies would provide a clearer understanding of EKG changes in patients undergoing SURD-AVR, along with an understanding of how these changes may intersect with pacemaker need, both in the shortand long-term. PPM after AVR is not without consequences $^{8}$; therefore, we cannot minimize the potential need for PPM after any aortic valve intervention.

\section{References}

1. Glauber M, Miceli A, Bacco L Di. Sutureless and rapid deployment valves: implantation technique from A to Z-the INTUITY Elite valve. Ann Cardiothorac Surg. 2020;9:417-23. https://doi.org/10.21037/acs-2020-surd-23-intuity
2. Glauber M, Miceli A, di Bacco L. Sutureless and rapid deployment valves: implantation technique from A to Z-the perceval valve. Ann Cardiothorac Surg. 2020;9:330-40. https://doi.org/10.21037/ACS-2020-SURD-23

3. Berretta P, Montecchiani L, Vagnarelli F, Cefarelli M, Alfonsi J, Zingaro C, et al. Conduction disorders after aortic valve replacement: what is the real impact of sutureless and rapid deployment valves? Ann Cardiothorac Surg. 2020;9:386-95. https://doi.org/10.21037/acs-2020-surd-26

4. Regeer MV, Merkestein LR, De Weger A, Kamperidis V, van der Klev, van Rosendael PJ, et al. Left bundle branch block after sutureless, transcatheter, and stented biological aortic valve replacement for aortic stenosis. EuroIntervention. 2017;12:1660-6. https://doi.org/10.4244/EIJ-D-15-00256

5. Thuraisingam A, Newcomb AE. Rhythm disturbances following rapid-deployment aortic valve replacement. J Thorac Cardiovasc Surg Tech. 2021;10:219-26.

6. Moskowitz G, Hong KN, Giustino G, Gillinov AM, Ailawadi G, DeRose JJ Jr, et al. Incidence and risk factors for permanent pacemaker implantation following mitral or aortic valve surgery. J Am Coll Cardiol. 2019;74:2607-20. https: //doi.org/10.1016/j.jacc.2019.08.10648

7. Sammour Y, Krishnaswamy A, Kumar A, Puri R, Tarakji KG, Bazarbashi N, et al. Incidence, predictors, and implications of permanent pacemaker requirement after transcatheter aortic valve replacement. JACC Cardiovasc Interv. 2021;14:115-34. https://doi.org/10.1016/j.jcin.2020.09.063

8. Glaser N, Persson M, Dalén M, Sartipy U. Long-term outcomes associated with permanent pacemaker implantation after surgical aortic valve replacement. JAMA Netw Open. 2021;4:e2116564. https://doi.org/10.1001/jamanetwork open.2021.16564 